\title{
Developing Vocabulary Knowledge among Low Achievers: Mobile Augmented Reality (MAR) Practicality
}

\author{
Ilyana Jalaluddin, Lilliati Ismail, and Ramiza Darmi
}

\begin{abstract}
Difficulty in learning gives huge impact to the process of language discovery among school children. LINUS students are categorized in this group and regarded as Low Achiever (LA) regardless of their education level. Currently, schools are provided with traditional learning materials such as textbook prepared by the Ministry of Education and it is up to the teachers' own creativity and initiative to turn the materials into a more interesting learning source [1], [2]. However, depending solely on these learning materials alone is not enough as these children will easily lose their attention as they become bored and finally lost interest to proceed with the learning process [3]. Therefore, there is a need to utilize the elements of technology in order to motivate and facilitate these LINUS students in learning vocabulary in English. This experimental study aimed to explore the effectiveness of using mobile augmented reality (MAR) application in vocabulary learning among LINUS students. 45 students were involved and the development of MAR in vocabulary learning in this study was investigated based on the ADDIE Instructional Design (ID) method as a framework. As a form of measurement, British Picture Vocabulary Scale (BPVS) III was used and findings showed that there was a significant improvement in the post test after 6 months of MAR implementation. Although this study showed an encouraging results, there was still lack of skills in terms of writing the words learnt via augmented reality. The results of this study provide the discussion on the practicality of using Augmented Reality to help the struggling learners to cope with acquiring and learning English language in ESL context.
\end{abstract}

Index Terms-Mobile augmented reality (MAR), vocabulary learning, ESL LINUS learners.

\section{INTRODUCTION}

Nowadays, using multimedia and computer aided instruction models has become a norm in education field. Two of the most common interactive multimedia applied are Augmented Reality (AR) and Virtual Reality (VR). Bonner \& Reinders [4] described AR as "the motion and information technologies that enable enhancing reality with digital resources", while VR as "the creation of entirely digital environments, in which users interact with information and other users". When using this interactive multimedia, apps on smartphones are required to display information through "trigger location-sensitive media" and VR will require additional tool such as headset to allow learners to feel the VR experience. In the field of sciences, AR is widely used especially in explaining the scientific concepts.

Manuscript received March 27, 2020; revised June 14, 2020. This work was supported by Universiti Putra Malaysia (UPM) under Grant 9598200.

Ilyana Jalaluddin and Ramiza Darmi are with the Department of English, Faculty of Modern Languages and Communication, UPM, 43400 Serdang Malaysia (e-mail: ilyana@upm.edu.my,ramiza@upm.edu.my).

Lilliati Ismail is with the Department of Languages and Humanities Education, UPM, 43400 Serdang, Malaysia (e-mail: lilliati@upm.edu.my).
Ma [5] for instance, discovered that 3D animation instruction actually improved learners' immediate learning effects on the concepts of basic sciences through research in the application of 3D animation learning. Ma [5] found that the students understood the phenomena, causes and periods of the moon phases, as well as the motions of the earth, the sun and the moon for instance. He concluded that interactive multimedia materials such as $2 \mathrm{D}$ and $3 \mathrm{D}$ animation is an effective tool as it helps to improve the learning effectiveness of the concepts of basic ideas in Sciences. In another Sciences research, it was found that instructional materials with augmented reality (AR) technologies base can effectively enhance the academic motivation of learners and help them obtain better learning effects [6]. Jung-Chuan Yen et al. [7] also pointed out that integrating the AR technologies in learning can actually solve problems caused by the following situations: the concepts of some subjects that may be excessively abstract; the surroundings for observation that cannot be easily constructed or meet the necessary requirements due to cost and technological limits or remote locations. In addition, researches on simulation-based learning showed that teaching which were aided by the interactive $2 \mathrm{D}$ or $3 \mathrm{D}$ models such as $\mathrm{AR}$ can significantly help learners understand spatial concepts [8].

Nevertheless, all these researches mostly focused on Sciences subject, as Bonner \& Reinders [4] has pointed out that "research into the use of AR and VR in language education is still in its infancy with most reports being of exploratory studies designed to investigate possibilities and student perceptions" such as Li et. al [9], Lu, Lou and Chung [10]. Thus, this study hopes to implement AR in a different context that is the English language learning classroom which is very limited currently for the LINUS learners especially. It is hoped that this kind of simulation-based e-learning system that is mobile Augmented Reality (AR) may help Malaysian LINUS learners not just gain interest but to obtain more knowledge in understanding and using spatial vocabulary in English language learning such as everyday vocabulary. This study focused more on spatial concepts as this concept emphasizes vocabulary that focuses on everyday objects, places and activities to reason out goals and solutions. By using spatial concept, LINUS learners who possess low ability to grasp fundamental knowledge [11] will able to make sense the real-world connection with what they have learnt. This spatial concept was delivered via Mobile Augmented-Reality (AR) which provided them explanation visually.

In Malaysia, students who are incompetent in mastering literacy and numeracy concepts has become the main issue in primary school level [12], \& [13]. Currently, these learners are identified as low achievers (LA) or more specifically slow 
learners. According to Malik [14] as cited in Ahmad \& Mutalib [15], "low achievers (LA) or slow learners refer to students with low cognitive ability to grasp fundamental knowledge in the mainstream education system". With this characteristic, this group of students struggle to cope in learning in the mainstream or normal stream and thus, the teachers must pay extra attention and effort in teaching them. Due to this, the Ministry of Education (MoE) of Malaysia implements Literacy and Numeracy Education program as part of Malaysia's key areas of educational success (NKRA) to curb this scenario. LINUS Screening test is then conducted to identify these low achievers. LINUS test questions are designed according to the students' level mainly Year 1, 2 and 3. The tests are basically divided into three different sets which are Bahasa Malaysia (literacy), English (literacy) and Mathematics (numeracy). According to the teachers, LINUS test is a guided test which means that the teacher will provide assistance when the students are answering the questions and at the end of the test, the students will be considered as incompetent if they were unable to perform despite the assistance given [16]. This screening test is conducted in March (Screening 1), Jun (Screening 2) and September (Screening 3).

Based on this standard test instrument, the teachers will then determine the child's ability in languages that are Malay Language and English Language, and numeracy that is Mathematics. Those who cannot answer the test well will be categorized as LINUS students and will be put in a remedial class called LINUS Remedial Class. The objective of this program is to give them a proper learning process [16]. In order to ensure a more effective learning methods been carried out, Ministry of Education (MoE) Malaysia has developed modules in the form of textbooks that can be used by teachers during the remedial session (Ministry of Education Malaysia official portal). In English language learning, this textbook contains many basics vocabularies related to daily actions with graphics to help the learners grasp meaning first and finally able to read and write simple sentences. According to Ministry of Education Malaysia (Ministry of Education Malaysia official portal), LINUS programme aims to help learners to be able to understand and use the language at word level and finally at phrase level in a non-text. In short, vocabulary learning is emphasized here in LINUS syllabus as it is believed that it will help to build up the English language proficiency as a whole in the end. However, to complement the usage of this textbook, the LINUS teachers' initiatives are very important. Here, teachers are encouraged to implement creative teaching approaches that blend in the use of information communication technology (ICT) as learning assistance for LA children [15].

\section{A. Struggle in Learning and Teaching Process}

Poor learning ability somehow hampers the learning process of school children in gaining knowledge. This is especially obvious among the low achiever students or also known as LINUS students at various education level. According to Malik [14], this category of children unfortunately neither can be put under the special education class nor can be categorized as having learning disabilities. Teacher however needs to provide proper attention and assistance to them as these children are unable to acquire understanding in most of the subjects, especially language and mathematics in normal class sessions. The learning characteristics of LA children can obviously be identified in the learning session in class as they possess low ability to grasp fundamental knowledge [11], perform poorly in standardized examination [12] and lack of motivation during learning process [17]. A similar problem can be seen in recent researches based on the observations that have been made when the children have test in year one, two and three [15], [12], [18]. According to Ahmad \& Abdul Mutalib [15], some of them cannot even read the questions and write the answer properly, which lead them unable to complete the test.

Even though the ministry has implemented the LINUS 2.0, its operation has faced some problems so far [19]. Previous researches [15] indicated that most of the teacher agreed that they have limited resources as they are being provided with LINUS workbook only by the MoE. The workbook consists of several volumes which contain graphical images that relate to everyday vocabularies with different methods of learning concept [2]. In order to enrich the learning materials, teachers have to take their own initiative and creativity to make their lessons interesting such as by creating flash cards, presentation slides, and extra exercises to help the learners grasp the meaning of words first before being able to use it [2]. According to the teachers, the scenario however becomes worse as these LINUS students often lose focus and are easily distracted during the learning process when the teacher uses common learning tools such as books, exercise sheets, flash cards and whiteboard [12]. Therefore, based on the previous studies, the teachers highlighted that they require teaching and learning assistance specifically designed and created for LINUS students' exercises in which they pointed out that computer based learning is essential to make English language a fun learning experience [2], [15], [3].

This is supported by Adam \& Tatnall [20] whom emphasized that learning assistance is important to provide the Low Achiever (LA) students with an attractive and attentive learning environment. Currently, most of the learning tools are provided by the MoE and they are more of traditional learning materials. It is up to the teachers' effort to fully utilize the materials using their own creativity and initiative [1], [2]. According to Eunice Ong Luyee et al. [21], the main and traditional teaching being practiced currently is actually the Varna Samooha Approach which is structured, participatory and child - centered teaching - learning methodology. However, solely depending on these learning materials alone is not enough as these children will easily lose their attention and, have low intention and motivation to proceed with learning process [3]. Therefore, there is a need to utilize the elements of technology in order to motivate and facilitate these LINUS learners in learning English language.

Unfortunately, technology-based learning is rarely implemented in learning there is no specific application or courseware created for the remedial class and the available courseware from textbook is not appropriate for their needs [15]. This can be observed from studies conducted by Ahmad \& Abdul Mutalib [15] in five different schools in Malaysia who found that most of these children were not exposed to the courseware in the market as it is not available at school and not suitable with LA children's level. Even though 
Ministry of Education has introduced Frog VLE application, it needs "web-based e-learning skill which is lacking in most LINUS students, even if they are IT literate children" [15]. Initial studies into the effectiveness of the literacy intervention program for English literacy also found that "the English teachers, unlike their Bahasa Melayu and Math counterparts, have to double up their effort as remedial teachers as well" [19]. Additionally, they are in dire need of the right remedial content and they also ask for assistance in preparing the teaching aids and content [2], [15]. According to Bokhari et al. [2], these problems should thus be addressed immediately by the Ministry of Education to ensure the success of the literacy intervention programme. Therefore, this study aimed to provide the LINUS students with a learning assistance using technological advancement in education. Here, a platform called UNITY was used to develop a simulation-based concept learning system on the vocabularies used in the LINUS textbook. UNITY is a cross-platform game engine that allowed Augmented Reality materials to be created for IOS and Android systems. Following this, the effectiveness of mobile simulation-based instructional models (AR) on the vocabulary development of LINUS learners will be further discussed in this article.

\section{THEORETICAL FRAMEWORK}

This study is based on the cognitive theory of multimedia learning (CTML) which consists of three underlying assumptions [22]: 1) humans have different compartment for processing visual/pictorial information and verbal/auditory information; 2) the compartment has a very limited capacity; 3) learning is an active process that requires coordinated cognitive processes. According to Mayer [23], CTML posits that for learning process to succeed, humans must select relevant words from text or narration and relevant images, establish both the words and images into coherent verbal and pictorial representations, and incorporate both representations with new knowledge. This can be represented in Fig. 1 below;

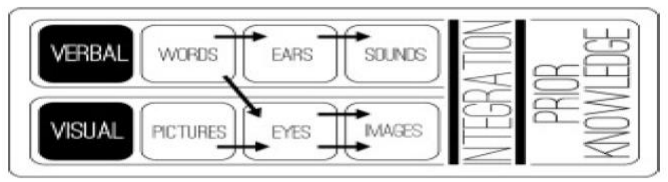

Fig. 1. Cognitive theory of multimedia learning. Source: Swerdloff [28].

Fig. 1 above shows that words can be processed in two ways. One, the spoken words or sound can be verbal stimulus for the ears, meanwhile, the pictures or written words are processed through the sensory memory (i.e. eyes) as visual stimulus. These two stimuli are then processed by the brain in working memory which later can be part of the prior knowledge. This process can be the framework of how multimedia applications can be utilized in the learning of language. Here, Mayer [23] emphasized that a multimedia instructional message is a communication containing words and pictures which can be delivered using book-based-communication (i.e. printed words and static graphics) and the computer-based communication enhanced through animation or video clips for textbook chapters. In this study, Ministry of Education (MoE) has prepared a printed LINUS textbook that emphasizes on the acquisition of daily vocabularies such as daily actions to describe daily activities. This study tried to enhance the textbook by developing MAR modules or learning materials to foster a more interactive learning and eventually promote understanding among LINUS learners. Mayer [23] claims that CTML is parallel with the principles of cognitive science, generate hypotheses that can be tested, is in line with the empirical research, and the most important aspect is its relevance to educational needs for improving the design of multimedia instructional messages.

\section{MATERIALS AND METHODS}

\section{A. Purpose}

In general, the purpose of this study was to examine the effectiveness of using simulation-based instructional design that is Mobile Augmented Reality on vocabulary learning in English language among students in LINUS program. In order to achieve these objectives, this experimental study aimed to find if there are any specific significance differences in terms of vocabulary development between the pre and post test of LINUS group after AR treatment with the following hypothesis;

$\mathrm{H}_{0}$ : There is no difference in vocabulary knowledge amongst LINUS class students after AR programme implementation.

\section{B. Design of the Study}

This study used pre-experimental method with one group pre-test and post-test design. The comparison between pre-test and post-test depend on the success of the treatment. The design can be described as $\mathrm{O} 1-\mathrm{X}-\mathrm{O} 2$ where $\mathrm{O} 1$ represents the Pre-test, $\mathrm{X}$ is the treatment and $\mathrm{O} 2$ is the Post-test.

\section{Participants}

Two groups of Year 2 students aged 8 years old from LINUS mainstream were involved in this study following the permission given by the Ministry of Education. These groups consisted of 45 students and both groups were from two primary schools in Selangor rural areas. Each group consisted of 23 and 22 students respectively. They were studied and involved in the MAR programme for 6 months.

\section{Stages in Data Collection}

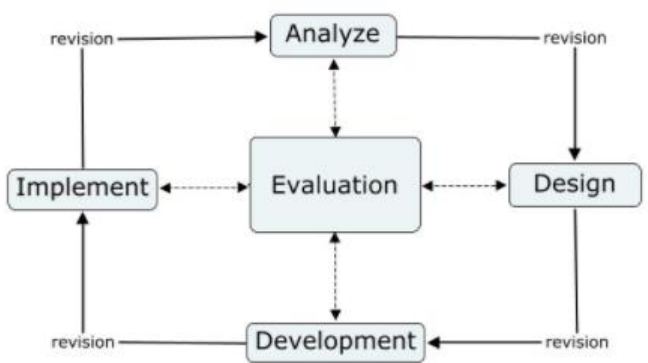

Fig. 2. ADDIE Model phases.

In this study, ADDIE Instructional Design (ID) method was used as a framework to design and develop MAR learning materials for students in LINUS program. There 
were five phases involved in the model to make sure that the process of before, during, and after using the MAR applications had achieved the objectives. These five phases are analysis (A), design (D), development (D), implementation (I) and evaluation (E) which can be depicted as in Fig. 2;

Based on these five phases, the process of this study is arranged into five main stages namely literature exploration (Analysis phase), developing the MAR learning materials (Design phase), pilot study (Development phase) and actual study (Implementation phase) and assessing the MAR learning materials (Evaluation phase). For actual (Implementation phase), the procedures of collecting data are chronologically as follows;

\section{1) Pre-test and post-test}

The researcher gave the students pre-test to know their achievement in English vocabulary. The vocabulary test was conducted using British Picture Vocabulary Scale III. After the treatment, the students were given the same vocabulary test.

\section{2) Treatment}

The researcher conducted a lesson for 6 months with the students by using vocabulary materials embedded with augmented reality (Fig. 3). There were two apps created for the purposes of the study namely finding the suitable vocabularies that represented the objects and the next one was exploring a room which was filled with the objects that they had learnt.

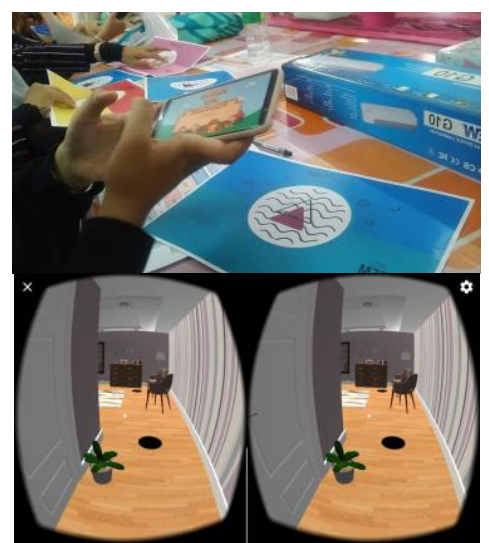

Fig. 3. Augmented Reality materials created for the lesson.

\section{E. Instruments}

\section{1) British Picture Vocabulary Scale III (BPVS III)}

BPVS II is a one-to-one test produced by GL Education Group that assesses a child's receptive vocabulary level. In this test, the researchers said a word for each question, and the students responded by selecting a picture from four options that best illustrates the word's meaning. There are 12 levels in the test which can indicate the age level of achievement. According to GL Education Group (GLE Education Group Website, 2018), for this test, no reading is required and thus, BPVS3 can be used to evaluate language development in non-readers and especially pupils with expressive language impairments. The assessment can be carried out for students with mild autism, other communication difficulties and English as an Additional Language (EAL) students because no spoken response is required.

\section{2) Software platforms}

In order to enrich the LINUS textbook, the researcher enhanced it by developing Mobile AR in learning. To enliven the textbook, the researcher created references based on vocabularies in the LINUS syllabus to physical AR fiducial markers. These handheld fiducial markers had 3D objects augmented on top of them and learners could actually physically manipulate them. According to this physical, manipulation was almost the same as interaction with any other physical object as it allowed the learners to rotate and tilt accordingly to the marker position. In this study, UNITY platform was a site that was fully utilized as it allowed the researchers to create and manage visual images. In addition, UNITY also allowed the researchers to connect digital content such as video images (using video platform) and animation (animation platform) in books and classroom wall.

\section{F. Analysis Procedures}

Paired sample T-test was used to determine whether any difference between the two time points (i.e. LINUS students' vocabulary performance before and after a 6-month learning using Augmented Reality) is statistically significant. 45 students' performance in vocabulary test was measured using British Picture Vocabulary Scales before and after they underwent a new form of language learning method to improve vocabulary knowledge that is Augmented Reality. After Paired sample T-test was run, a qualitative analysis was conducted by analyzing the words written by the learners at the end of the program. After 6-months, the learners were then asked to spell the words that they learnt throughout the 6-months period. This was a spelling test to identify the learners' accuracy in writing the words that they learnt through the visual and sensory stimulus via AR apps. In total, there were 15 images that the learners had to identify and write the words that described the images. These 15 images were taken from BPVS book and all the images were consistent with Ministry of Education curriculum.

\section{FINDINGS}

\section{A. Age Equivalent}

Based on the British Picture Vocabulary Scale (BPVS) III, the age equivalent norms were able to be reported. The age equivalent indicates the age at which a given raw is an average accomplishment for the group on whom the test was standardised. In the standardization sample, 38 out 45 students did not have a valid age equivalent to $8: 84 \%$ had a raw score that corresponded to an age below those used in the sample and $16 \%$ had a raw score that corresponded to an age equivalent those used in the sample as shown in Table I below;

TABLE I: AGE EQUIVALENT BASED ON THE RAW SCORES

\begin{tabular}{|c|c|}
\hline Age Equivalent & Number of students \\
\hline 4 & 9 \\
\hline 5 & 9 \\
\hline 6 & 11 \\
\hline 7 & 10 \\
\hline 8 & 6 \\
\hline
\end{tabular}

Based on Table I above, it can be seen that majority of Year 2 equivalent age were below the standardised age that 
was 8 years old. 9 students' raw scores were reported to be equivalent to the age of 4 years old and another 9 students' performance was equivalent to 5 years old. 11 students' raw scores corresponded to the age of 6 years old and 10 students' performance corresponded to age equivalent of 7 . Only 6 students however managed to score equivalent to actual age standardisation of 8 . Despite the unparalleled age equivalent based on the performance scores, the students still showed slight improvement in terms of vocabulary level after the implementation of the augmented reality in learning of English language.

\section{B. Vocabulary Performance}

In order to analyse the differences between the pre and post-test, a paired sample t-test was run. Before running the test, the assumption of normality and outliers were tested on the differences between the paired values. Based on the inspection of the boxplot as presented in Fig. 4 below, there were no outliers in the data as assessed by inspection of a boxplot greater than 1.5 box-lengths from the edge of the box below;

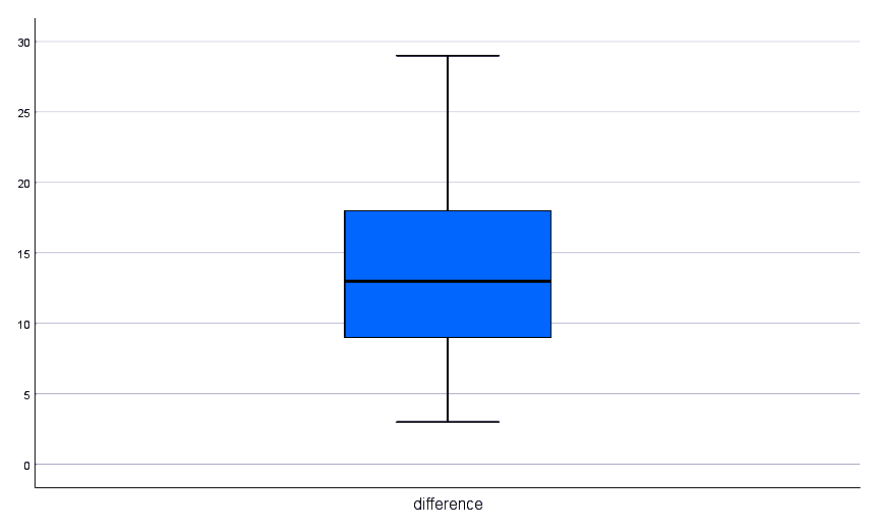

Fig. 4. Boxplot of mean differences between pre and post test.

Next, to run the normality test, Shapiro-Wilk was used as this research had a small sample size that was less than 50 participants. The result of the Shapiro-Wilk test can be presented as in Table II below;

TABLE II: TESTS OF NORMALITY

\begin{tabular}{lcccccc}
\hline \multicolumn{1}{c}{ TABLE II: TESTS OF NORMALITY } \\
\cline { 2 - 7 } & \multicolumn{3}{c}{ Kolmogorov-Smirnov ${ }^{\text {a }}$} & \multicolumn{3}{c}{ Shapiro-Wilk } \\
\hline Statistic & df & Sig. & Statistic & df & Sig. \\
\hline difference & .081 & 45 & $.200^{*}$ & .975 & 45 & .526 \\
\hline
\end{tabular}

*. This is a lower bound of the true significance.

a. Lilliefors Significance Correction

Based on the table above, it can be concluded that the differences between the pre-test vocabulary scores and the post-test vocabulary scores were normally distributed, as assessed by Shapiro-Wilk's test $(p=.526)$. Roughly, descriptive statistics from the output indicated that students performed better when Augmented Reality was implemented in the learning and teaching process $(64.36 \pm 22.918)$ as opposed to before the Augmented Reality was used (50.84 \pm 20.914). This can be portrayed as in Table III below;

TABLE III: PAIRED SAMPLES STATISTICS Mean N Std. Deviation Std. Error Mean

\begin{tabular}{rllll} 
& Mean & $\mathrm{N}$ & Std. Deviation & Std. Error Mean \\
\hline Pair 1 Post test score & 64.36 & 45 & 22.918 & 3.416 \\
\hline Pretest repeat & 50.84 & 45 & 20.914 & 3.118 \\
\hline
\end{tabular}

In order to determine the magnitude of the mean difference between the pre and post-test, a paired sample test was referred to, including the standard deviation, standard error of the mean and $95 \%$ confidence intervals as represented in Table IV below;

TABLE IV: PAIRED SAMPLES TEST

\begin{tabular}{|c|c|c|c|c|c|c|c|c|}
\hline & \multicolumn{5}{|c|}{ Paired Differences } & \multirow{3}{*}{$\mathrm{t}$} & \multirow{3}{*}{ df } & \multirow{3}{*}{ is $\frac{0}{\frac{0}{7}}$} \\
\hline & \multirow[b]{2}{*}{$\stackrel{\Xi}{\stackrel{\Xi}{\Sigma}}$} & \multirow{2}{*}{ 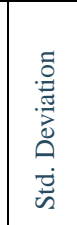 } & \multirow{2}{*}{ 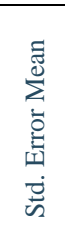 } & \multicolumn{2}{|c|}{$\begin{array}{c}95 \% \\
\text { Confidence } \\
\text { Interval of the } \\
\text { Difference }\end{array}$} & & & \\
\hline & & & & $\overbrace{3}^{0}$ & 芯 & & & \\
\hline $\begin{array}{l}\text { Post test score } \\
\text { Pretest repeat }\end{array}$ & 13.511 & 5.833 & .870 & 11.759 & 15.264 & 15.537 & 44 & .000 \\
\hline
\end{tabular}

As $p<.0005$ in the table above, it can be concluded that there is a statistically significant mean difference between the means of the two scores groups (i.e. pre and post-test). All in all, it can be reported that the students' performance in vocabulary elicited a statistically significant increase when Augmented Reality was implemented in learning process compared to the initial stage that was before the implementation of Augmented Reality, $t(44)=15.537, p$ $<.0005$.

Statistically, results showed that the learners improved in terms of vocabulary performance after the implementation of the program. Nevertheless, when it came to spelling the words on paper, the learners still depicted spelling errors in which the spelling mimicked the sound or pronunciation of the words that the learners actually hear. For instance, 'book' was spelt as 'buk' and the rest of the examples can be seen Table V below;

TABLE V: LIST OF SPELLING WORDS

\begin{tabular}{|c|c|c|}
\hline No. & $\begin{array}{c}\text { Words the students hear in the } \\
\text { program and read from the BPVS book }\end{array}$ & $\begin{array}{c}\text { Words written by the } \\
\text { students on paper }\end{array}$ \\
\hline 1 & Cat & Kat \\
\hline 2 & Fish & Pis \\
\hline 3 & Climb & Kelimb \\
\hline 4 & Jump & Jam \\
\hline 5 & Train & Terain \\
\hline 6 & Comb & kom \\
\hline
\end{tabular}

The list of words above show that the students were able to identify orally what are the images (i.e. objects or actions) that they saw in the book. Then they were later asked to spell the word that described the images. Spelling errors persist however, but in comparison to earlier stage in which they couldn't even read or write, the students now are able to write the words to represent the images. This scenario represents the cognitive processes of the LINUS learners and we can see part of CTML theory succeed in this program. This is because the learners' verbal stimulus (i.e. what their ears hear) are able to help the learners to produce knowledge (written words). Even though the teachers showed the words (visual stimulus) along with the sound to explain the images throughout the 6-months program, the learners somehow processed the sound more than the visual words. This finding indicates the learners are able to identify images by pronouncing the words. However, in terms of written words, the learners produced more of 'pronunciation spelling' that is spelling words based on how they are pronounced (in this study, based on what they heard in the program). This calls 
for a change in the teaching and learning approach for low achievers and learners with learning difficulties. This might indicate that learners may not able to process printed words as fast as the normal learners, but with sound and visual, it assists the learners' cognitive process as what CTML suggested. But with more and long duration of learning time, this group of learners may be able to process through both of visual and sensory stimulus successfully.

\section{DISCUSSION}

Much of the existing research on augmented reality have been conducted in Sciences field and already demonstrated the intervention's positive influence in helping the students to understand sciences concepts. The results of this study have also showed some of those findings but it has gone beyond by showing it is possible to create a better learning environment for struggling learners in learning language. This study has demonstrated significant improvement after the implementation of Augmented Reality in the learning materials. This somehow shed a light that augmented reality was able to help these remedial students or better know as LINUS to learn or perhaps grasp a basic concept of English language words. The results is consistent with the existing literature by demonstrating the use of AR in the classroom has positive implications for students' understanding even though they are from different field. However, in comparison to previous studies [7], [24], [25], this study made a difference by examining the effect of augmented reality on language learning targeted at low-achiever learners that is LINUS learners. It also tries to describe the words spelt by the learners in writing rather than measuring their performance quantitatively only. Words identified from the learners' writings indicate that the learners spelt the words based on the character's speech (what they hear) rather than the correct spelling. This has caused a lot of misspelling but the misspelled words actually represented the images correctly. This potrays that spoken form of English is perceived differently from the written form for these LINUS learners or more specifically low achievers. It should be noted that these learners were unable to read and write before the program had started and at the end of the 6-months program, the learners finally were able to produce not just correct spoken words but also write them on paper despite the misspelling that they had. This gives the impression that the visual and sensory stimulus created via MAR apps are able to stimulate their cognitive process by creating their prior knowledge. The knowledge that they gained via what they hear and see finally helped the learners to 'visualize' the written words though not that accurately spelt. Here, the prior knowledge from the sensory stimulus nevertheless impact further of their performance. This provides platform and idea to the educators on what to emphasize when creating and developing the 21 st century and smart interactive classroom for this group of learners.

With the aims of empowering 21st century learning and smart interactive classroom as encouraged by Prime Minister, Tun Dr Mahathir Mohammad [26], the results of this study could promote the use of augmented reality. As Ismail and Aziz [27] have noted that equal access to robust learning experiences and suitable environment are essential for successful learning regardless of the students' academic level. In this study, augmented reality usage in understanding spatial vocabulary has helped the LINUS students to grasp not just the meaning, but the concept of how to pronounce the words. The students were able to describe the pictures using the words that they have learnt after the implementation of the augmented reality application even though spelling errors persist. Thus, it is imperative to conduct similar studies with various ages in both rural and urban areas to get a larger samples and context of impact. If augmented reality can be used with other groups and longer duration, it can be an important step in helping the struggling learners to cope with acquiring and learning English language.

\section{CONCLUSION}

In this study, Mobile AR learning materials were built to connect the LINUS learners' understanding to the real worlds. It is hoped that by incorportating MAR learning materials in the teaching and learning of LINUS students, the concepts or vocabularies that seem so abstract to LINUS students become more visible and visualized. This will be of great benefit to LINUS learners in terms of promoting their understanding towards the concepts and engage in their learning better. In this study, MAR learning materials are developed with the possibility of turning abstract vocabularies to concrete and, how these vocabularies can actually been applied or used in the real world. Preliminary findings showed that MAR apps maybe suitable to be used to help struggling ESL learners to understand vocabulary in context. However, in order to go beyond understanding the text, MAR app may need to be more advanced by providing 3D images that allow the learners to manipulate the objects. By engaging and manipulating, it will enhance learners' understanding better.

\section{CONFLICT OF INTEREST}

The authors declare no conflict of interest.

\section{AUTHOR CONTRIBUTIONS}

Ilyana Jalaluddin, Lilliati Ismail and Ramiza Darmi conducted the research and jointly wrote the paper. Ilyana Jalaluddin analyzed the data and designed the program. Lilliati Ismail and Ramiza Darmi reviewed and improved the article. All authors had approved the final version.

\section{ACKNOWLEDGMENT}

The authors would like to acknowledge the financial and technical support of Universiti Putra Malaysia in the production of this work. Our recognition for Ministry of Education Malaysia and Secondary Schools in Selangor, a key factor for the project realization.

\section{REFERENCES}

[1] A. J. Othman, N. Normarini, G. Darusalam, and S. Siraj, "Cabaran guru program LINUS dalam pengajaran dan pembelajaran Bahasa," Issues in Education, vol. 34, pp. 37-51, October 2011.

[2] R. Bokhari, S. Md Rashid, and C. S. Heng, "Teachers' perception on the implemention of the literacy, numeracy and screening (LINUS LBI 2.0) programme among lower primary ESL pupils," Malaysian Journal of ELT Research, vol. 11, no. 1, pp. 108-121, 2015.

[3] T. S. Hoon, T. S. Chong, N. A. Ngah, and K. L. Kee, "The effectiveness of an interactive courseware using three different 
strategies," presented at International Conference on Information Communication Technologies in Education (ICICTE), Corfu, Greece, July 2-4, 2009.

[4] E. Bonner and H. Reinders, "Augmented and virtual reality in the language classroom: Practical ideas," Teaching English with Technology, vol. 18, no. 3, pp. 33-54, December 2018.

[5] J. Z. Ma, "Teaching effects of 3D animation applied to science learning in the fourth graders: The case of moon-phase conception," Master thesis, National Taitung University, Taiwan, 2008.

[6] C. H. Chen, F. G. Wu, and S. K. Zhung, "Design and augmented reality teaching system with concept mapping technique," presented at the 53rd Annual conference of JSSD, Japan, August 10, 2006.

[7] Jung-Chuan Yen, Chih-Hsiao Tsai, and Min Wu, "Augmented reality in the higher education: Students' science concept learning and academic achievement in astronomy," Procedia - Social and Behavioral Sciences, vol. 103, pp. 165 -173, November 2013.

[8] B. E. Shelton and N. R. Hedley, "Using AR for teaching earth-sun relationships to undergraduate geography students," presented at the 1st IEEE Int. ARToolkit Workshop, Darmstadt, Germany, October 7, 2002.

[9] S. Li, Y. Chen, D. M. Whittinghill, and M. Vorvoreanu. (June 2014). A pilot study exploring augmented reality to increase motivation of Chinese college students learning English. [Online]. Available: https://peer.asee.org/19977

[10] H. M. Lu, S. J. Lou, C. Papa, and C. C. Chung, "Study on influence of adventure game on English reading confidence, motive and self-efficacy," in Proc. International Conference on Technologies for E-Learning and Digital Entertainment, 2011, pp. 430-434.

[11] K. L. Lau and D. W. Chan, "Identification of underachievers in Hong Kong: Do different methods select different underachievers?" Educational Studies, vol. 27, no. 2, pp. 187-200, June, 2001.

[12] N. Sani and A. R. Idris, "Implementation of Linus programme based on the model of van meter and van horn," The Malaysian Online Journal of Educational Science, vol. 1, no. 2, pp. 25-36, April 2013.

[13] N. Sani and A. R. Idris, "Identifying the challenges encountered by teachers in dealing with indigenous students," Malaysian Online Journal of Educational Management, vol. 1, no. 3, pp. 48-63, October 2013.

[14] S. Malik, "Effect of intervention training on mental abilities of slow learners," International Journal of Education Science, vol. 1, no. 1, pp. 61-64, July 2009.

[15] S. Z. Ahmad and A. A. Mutalib, "Preliminary study: An investigation on learning assistance requirement among low achievers in primary schools," International Journal of Computer Applications, vol. 114, no. 2, pp. 48-54, March 2015.

[16] W. F. W. Ahmad, M. S. Noordin, and N. S. M. Shariffuldin, "Development of a multimedia courseware for slow learner children with reading difficulties: MyLINUS," in Proc. 3rd International Visual Infomatics Conference 2013, Raul A. Herrera-Acuña, V. Argyriou, S. A. Velastin, H. B. Zaman, P. Robinson, P. Olivier, and T. K. Shih, Eds. Switzerland: Springer International Publishing, 2013, pp. 371-382.

[17] K. L. Lau and D. W. Chan, "Motivational characteristics of under-achievers in Hong Kong," Educational Psychology, vol. 21, no. 4, pp. 417-430, July 2001.

[18] N. I. Azmi, M. Hisyam, and M. Hashim, “Amalan pengajaran berkesan dalam pendidikan asas vokasional di sekolah menengah kebangsaan harian: Dapatan kajian rintis," presented at 2nd International Seminar on Quality and Affordable Education (ISQAE 2013), Johor Bahru, October 7, 2013

[19] H. Azman, "Implementation and challenges of English language education reform in Malaysian primary schools," 3 L: Language, Linguistics, Literature, vol. 22, no. 3, pp. 65-78, 2016.

[20] T. Adam and A. Tatnall, "Use of ICT to assist students with learning difficulties an actor-network analysis," in IFIP Advances in Information and Communication Technology, N. Reynolds and M. Turcsanyi-Szabo, Eds. New York: Springer Verlag, 2010, pp. 1-11.

[21] O. L. Eunice, F. I. Roselan, N. H. Anwardeen, and F. H. M. Mustapa, "Suitability of the literacy and numeracy screening (LINUS) 2.0 programme in Assessing children's early literacy," The Malaysian Online Journal of Educational Science, vol. 3, no. 2, pp. 36-44, April 2015.

[22] R. E. Mayer and R. Moreno, "A coherence effect in multimedia learning: The case for minimizing irrelevant sounds in the design of multimedia instructional messages," Journal of Educational Psychology, vol. 92, no. 1, pp. 117-125, Jun 2000.

[23] R. E. Mayer, Multimedia Learning, Cambridge, UK: Cambridge University Press, Section IV, 2005.

[24] J. M. Gutierrez and M. D. Fernandez, "Augmented reality environments in learning, communicational and professional contexts in higher education," Digital Education Review, vol. 26, pp. 22-35, December 2014

[25] T. Haase, N. Weisenburgerm, U. F. Termath, D. Bergmanb, and M Dick, "The didactical design of virtual reality-based learning environments for maintenance technicians," in Virtual, Augmented and Mixed Reality: Applications of Virtual and Augmented Reality, R. Shumaker and S. Lackey, Eds. London: Springer, 2014, pp. 27-38

[26] Anon. (May 2019). Classroom of future goes digital. The Star [Online] Available:

https://www.thestar.com.my/metro/metro-news/2019/05/25/classroom -of-future-goes-digital

[27] M. I. H. Ismail and A. A. Aziz, "TS25 school teachers' perceptions of differentiated learning in diverse ESL classrooms," Journal of Education and Social Sciences, vol. 13, no. 1, pp. 95-107, June 2019.

[28] M. Swerdloff, "Online learning, multimedia, and emotions," in Emotion, Technology, and Learning, S. Y. Tettegah and M. P. McCreery, Eds. New York: Elsevier, 2016, Ch. 8, pp. 155-175.

Copyright (C) 2020 by the authors. This is an open access article distributed under the Creative Commons Attribution License which permits unrestricted use, distribution, and reproduction in any medium, provided the original work is properly cited (CC BY 4.0).

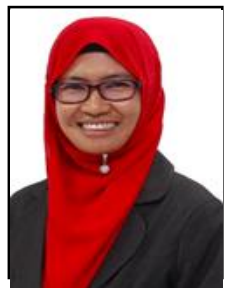

Ilyana Jalaluddin was born in Perak, Malaysia. She received her B.Ed in English language studies and Education from University of Otago, New Zealand in 2002 and M.Ed in teaching of English language as a second language (TESL) from Universiti Malaya Malaysia in 2006. She later obtained her Ph.D specialising in TESL in 2011 and her Ph.D research focused on the development of writing skills among rural area learners. She has researched and published book and articles related to TESL, teaching of writing skills, ESL writing skills and self-efficacy development. She also has received the MELTA Excellence in English Language Education Research Award in 2011 and few gold medals in language and technology competition in year 2019 and 2020. Currently, she is a senior lecturer at the Faculty of Modern Languages and Communication, Universiti Putra Malaysia. Her current research focuses on the use of technology in teaching and learning of writing skills under the University Impact Grant Research 2018-2020. Dr Ilyana Jalaluddin is also a member of Malaysia English Language Teaching Association.

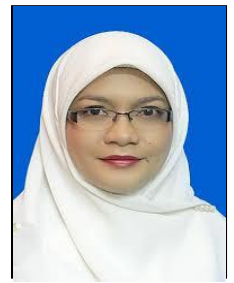

Lilliati Ismail was born in Kuala Lumpur, Malaysia She obtained a PhD in the teaching of English as a second language (TESL) in 2013 from Universiti Putra Malaysia, and M.Ed in TESL from Universiti Malaya, Malaysia in 2006 and a B.Ed (hons) in secondary education and English language teaching from the University of Exeter, UK in 1999. She is currently a senior lecturer at the Department of Language and Humanities Education, Faculty of Educational Studies, Universiti Putra Malaysia in Selangor, Malaysia. Before joining Universiti Putra Malaysia, she was a lecturer at a teacher training institute for 2 years and a secondary school English language teacher for 14 years. Her recent publications include the chapters entitled "Differentiated instruction in the L2 classroom" and "Oral corrective feedback in the L2 classroom" in the book "TESL Primer 2" published by UPM Press, Serdang, Selangor in 2019, research articles entitled "Effectiveness of using a tracker chart to enhance willingness to communicate among ESL learners in a philosophical inquiry classroom discussion" in Pertanika Journal of Social Sciences and Humanities, 28(S2), 233-245 (scopus-indexed) in 2020 and "Scaffolding speaking tasks using videoblog portfolio in an ESL classroom" in Universal Journal of Educational Research, 8(1A), 44-52 (scopus-indexed) in 2020. Her research interests include grammar instruction, teacher training and ELT methodology. Dr. Lilliati Ismail is a member of AsiaTEFL, and a recipient of Excellent Service Awards in 2006 and 2018.

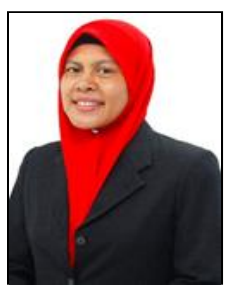

Ramiza Darmi is a senior lecturer in the Department of English, Faculty of Modern Languages and Communication, Universiti Putra Malaysia. She specialises in English language learning. Her research interests include English language learning, second language learning and technology-enhanced language learning. She obtained her PhD from School of Education, Faculty of Business, Education, Law and Arts, University of Southern Queensland, Queensland, Australia under the supervision of Professor Peter Albion and Associate Professor Jeong-Bae Son. 